Case Report

\title{
UNILATERAL HIGH DIVISION OF BRACHIAL ARTERY: A CASE REPORT AND LITERATURE REVIEW
}

\author{
Vishal Kumar ${ }^{1} \&$ Pretty Rathnakar $^{2}$ \\ ${ }^{1}$ Associate Professor, ${ }^{2}$ Assistant Professor \\ Department of Anatomy, K.S. Hegde M edical Academy, Nitte University, M angalore - 575 018, Karnataka, India. \\ Correspondence: \\ Vishal Kumar \\ Associate Professor, Department of Anatomy, K.S. Hegde M edical Academy, Nitte University, Mangalore - 575 018, Karnataka, India. \\ Mobile : +919845358754 E-mail : vishalkumarmd@gmail.com

\begin{abstract}
:
There are many articles reporting anomalies of various blood vessels of upper extremity. In the present article, we are reporting a case of high division of brachial artery into medial and lateral branches, $9.5 \mathrm{~cm}$ distal to the lower border of teres major muscle. It was also observed that the two branches are crossing over near the lower part of front of arm and the lateral branch continued into the cubital fossa and trifurcated at the proximal border of pronator teres muscle. We have discussed the anatomy, embryological basis, and clinical implications of these variations along with relevant literature review. The importance of knowledge about these variations in therapeutic and diagnostic interventions is discussed.
\end{abstract}

Keywords: development, radial artery, ulnar artery, high-up division.

\section{Introduction:}

The brachial artery (BA) is a continuation of the axillary artery. It begins at the distal border of tendon of teres major muscle and ends about a centimetre distal to the elbow joint at the level of neck of radius, by dividing into two branches lateral one is called radial artery (RA) and medial one is ulnar artery(UA) ${ }^{1,2}$. According to Compendium of Human Anatomic Variation, major variations are present in about $25 \%$ of the subjects studied for the brachial artery ${ }^{3}$.

Frequently the artery divides more proximaly into radial, ulnar and common interosseous arteries. M ost often radial arises more proximally, leaving a common trunk for ulnar and common interosseous ${ }^{1}$. Proximal division of $B A$ is due to the failure to disappear proximal origin of RA and the RA does not establish new connection with main trunk near

\begin{tabular}{|c|}
\hline Access this article online \\
\hline Quick Response Code \\
\hline
\end{tabular}
routine procedures like, blood pressure recordings and arteriography of different parts of body. Variation in the branching pattern of brachial artery is noteworthy for vascular surgeons particularly in cases involving traumatic injuries. Radiologists also must be aware of these kinds of variations during various imaging studies. Distal part of brachial artery is chosen for pulsed dopler sonographic measurments ${ }^{5}$.

The aim of our case study is to discuss the anatomy, embryological reasons for these kinds of variation and clinical significances along with relevant review of literature.

\section{Case Report :}

During routine dissection of upper limb for medical students in our medical academy we detected a case of higher division of brachial artery on the right side in a middle aged male cadaver. (Figure.1)

The brachial artery bifurcated into a medial and lateral branch $9.5 \mathrm{~cm}$ distal to the lower border of teres major muscle (Figure.1). After origin both branches runs inferiorly. The medial branch crosses superficial to the lateral branch and median nerve from medial to lateral side in the arm. (Figure.1) The lateral branch runs deep to medial branch and lateral to median nerve in the arm. 
In the fore arm the lateral branch runs superficially as radial artery. (Figure.1).

The medial branch runs deep to pronator teres muscle in cubital fossa and trifurcated at the proximal border of pronator teres muscle. One branch continued as similar course as that of ulnar artery forming the superficial palmar arch.The other two branches were muscular and common interosseous arteries (Figure.1).

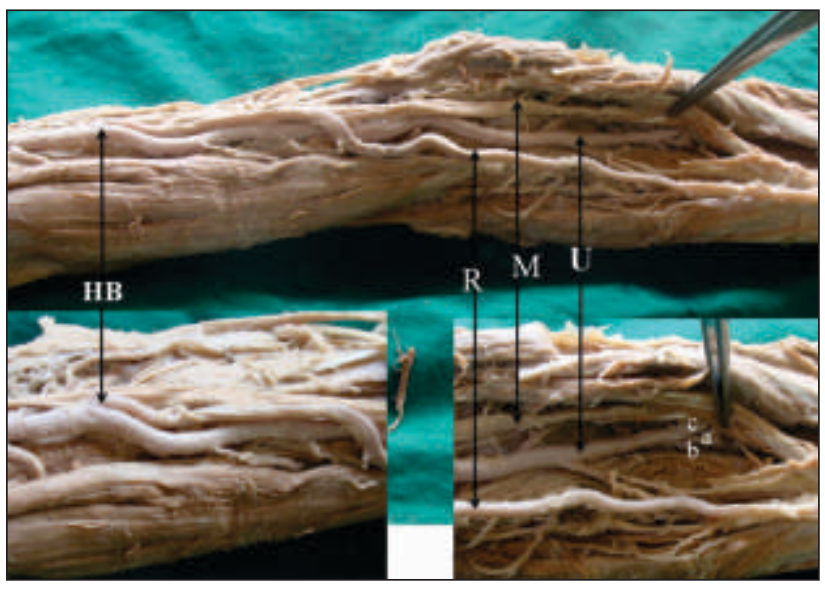

Figure 1 : High division of brachial artery and crossing branches. (inset figures showing enlarged view). HB- High division of brachial artery, R- Radial artery, M - M edian nerve, U- Ulnar artery, a - common interosseus artery, b - muscular branch, c - terminal ulnar artery.

\section{Discussion:}

Arterial variation in the upper limb was noted for the first time by von Haller in $1813^{6,7}$. It is not uncommon to find variation in the branching pattern of arteries of the upper limb.

The anomalies of various blood vessels of upper extremity can be explained on the basis of embryological development of the vascular plexus of limb buds. The early limb bud receives blood via inter segmental arteries, which contribute to a primitive capillary plexus. At the tip of the limb bud there is a terminal plexus that is constantly renewed in a distal direction as the limb grows. Later one main vessel supplies the limb and the terminal plexus; it is termed the axis artery ${ }^{9,10}$.

Arey and Jurjus mentioned six explanations for the variations in the blood vessels of upper limb ${ }^{11,12}$ :
1. The choice of unusual paths in the primitive vascular plexus.

2. The persistence of vessels which are normally obliterated.

3. The disappearance of vessels which are normally retained.

4. An incomplete development.

5. The fusion and absorption of parts which are normally distinct.

6. A combination of factors leading to an atypical pattern normallyencountered.

Thus persistence of the upper portion of the radial artery arising from the brachial artery proximal to the origin of ulnar artery followed by failure of development of the new connection of the radial artery with the brachial artery at the level of origin of ulnar artery ${ }^{13}$.

Alteration of any factor leads to deviation from the usual way. These are important from clinical and surgical point of view $^{14}$.

Serial sections of human embryos (224 upper limbs) are studied and then three-dimensional computer-aided reconstruction was performed to establish the normal pattern of development of the arteries of the upper limb of human embryos between stages 12 and 23, and to establish when and how variations occur'. Ozcan et al. classified arterial variations in the $\mathrm{arm}^{5}$.

The brachial artery is the proximal part of this axis artery while the distal portion, beyond the cubital fossa, is the interosseous artery. The radial and ulnar arteries arise relatively late in development as new vessels branch from brachial and interosseous arteries respectively ${ }^{15}$.

Treves and Rogers described a type of variant of brachial artery as presence of two arteries instead of one brachial artery. These two arteries may be a) radial and ulnar b) $2^{\text {nd }}$ branch may be interosseous which has originated high up ${ }^{16}$.

There is a case reporting division of the brachial artery in the upper third of the arm into radial and ulnar arteries, about $4 \mathrm{~cm}$ distal to the lower border of teres major 
muscle $e^{17}$.

An unusually short segment brachial artery with high up division of brachial artery at the level of insertion of coracobrachialis in the middle of the right arm was observed by Satynarayana N. The brachial artery was 11.5 $\mathrm{cm}$ in length and having slightly less calibre than usual. However it bifurcated normally into radial and ulnar arteries $^{6}$.

Shewale noted in the left upper limb of a male cadaver, bifurcation of brachial artery into radial and ulnar arteries at the lower border of teres major. Both the arteries had superficial course ${ }^{16}$.

In another case which is almost similar to our findings the brachial artery divided into radial and ulnar arteries after a short course in the upper half of the arm. The radial artery was located medially and the ulnar artery laterally. In its further course the radial artery, was located laterally after crossing the ulnar artery. Further course of the ulnar artery was as usual ${ }^{18}$. Higher division of the brachial artery is noted in 2 cases, where brachial artery bifurcated in the middle of the arm into radial and ulnar artery and in another case high origin of radial artery was observed ${ }^{6,7}$.

The brachial artery divided into radial and ulnar arteries, about $1.5 \mathrm{~cm}$ distal to the lower border of teres major muscle, in the upper third of arm. Which course superficial to forearm flexors ${ }^{19}$. High origin of radial and ulnar artery forms the highest percentage of variations of brachial artery. High origin of radial artery occurance is 3 to $15 \%$, as reported by different authors ${ }^{19,20}$. Bilateral high division of

\section{References:}

1. Standring S. Gray's anatomy: the anatomical basis of clinical practice. In: Upper arm Chapter 50. Spain: 39 ${ }^{\text {th }}$ edn. 2006; pp. 856, Elsevier Churchill Livinstone, New York.

2. Romanes G]. Cunningham's manual of practical anatomy. In: Upper limb and lower limbs, Vol.1. 15 ${ }^{\text {th }}$ edn. 1999; pp. 82, Oxford University Press, New York.

3. Bergman RA, Thompson SA, Afifi AK, Saadeh FA. Compendium of human anatomic variation, 1988, Urban \& Schwarzenberg, Baltimore.

4. Shewale SN, Sukre SB, Diwan CV. Bifurcation of brachial artery at its commencement: A case report. Biomedical Research. 2012; 23(3): p. 453-456.

5. Ozcan H, Oztekin PS, Zergeroglu AM, Ersöz G, Fiçicilar H, Ustüner E. Doppler ultrasound evaluation of the structural and hemodynamic changes in the brachial artery following two different exercise brachial artery were observed during routine dissection by Harbans Singh ${ }^{21}$.

A case of bilateral high division of brachial artery was reported by Puspalata M. Radial artery passes downwards and laterally. Ulnar artery passes downwards and medially. In cubital fossa it passes deep to the ulnar head of pronator teres muscle ${ }^{22}$.

The high division of the brachial artery observed in an individual, situated $20 \mathrm{~cm}$ above the cubital fossa and 8.5 $\mathrm{cm}$ below the axilla, in the right arm and $21.5 \mathrm{~cm}$ above the cubital fossa and $7.0 \mathrm{~cm}$ below the axilla in the left arm by Rossi et $\mathrm{al}^{23}$. Radial artery has been used for harvesting in cardiovascular diseases especially in coronary artery bypass grafting. In recent advances the radial artery is used in reconstructive micro vascular surgeries and also in plastic surgeries ${ }^{6,7,8}$.

\section{Conclusion:}

Thus any of the factors affecting during development of limb vessels will lead to anomalies in the level of division of major arteries. These variations are having practical importance for the radiologists, cardiologists and orthopedic and vascular surgeons. Last but not the least, knowledge of this variation is important for the clinicians in day to day practice for measurement of blood pressure using sphygmomanometer cuff in the arm. Any patient visiting to causality full imaging of this branching pattern is s neither feasible, nor cost-effective. Hence it is important to keep in mind possibility of this kind of variation before initiating any procedure.

protocols. Diagn. Interv. Radiol. 2006; 12(2) p. 80-84

6. Bidarkotimath S, Avadhani R, Kumar A. Primary pattern of arteries of upper limb with relevance to their variations. Int. J. Morphol. 2011; 29(4). p. 1422-1428.

7. Bidarkotimath $S$, Avadhani R, Kumar A, An anatomical study of primary pattern of arteries of upper limb with relevance to their variations. NUJHS. 2012; 2(1) p. 08-14.

8. Agrawal D, Singh N, Mohanty BB, Chinara PK. Variation in the branching pattern of axillary artery - a case report. Int J Anat Var. 2013; 6. p. 31-33.

9. Rodriguez-Baeza A, Nebot J, Ferreira B, Reina F, et al. An anatomical study and ontogenetic explanation of 23 cases with variations in the main pattern of the human brachio-antebrachial arteries. J Anat. 1995; 187 p. 473-479. 
10. Patnaik, VVG, Kalsey G, Singlarajan K. Branching pattern of brachial artery-A M orphological Study. J Anat. Soc. India. 2002; 51(2). p. 176186.

11. Kachlik D, Konarik M, Baca V. Vascular patterns of upper limb: an anatomical study with accent on superficial brachial artery. Bosnian journal of basic medical sciences. 2011; 11 (1). p. 4-10.

12. Arey LB. Developmental Anatomy. $6^{\text {th }}$ ed. Philadelphia, WB. Saunders. 1957; p. 375-77.

13. Satyanarayan N, Sunita P, Sheikh M M, Devi SP. Brachial artery with high up division with its embryological basis and clinical significance. Int J Anat Var. 2010; 3. p. 56-58.

14. Hollinshed WH. Anatomy for Surgeons. Vol. 3. 1958; pp. 66-73, Hoeber and Harper Inc, New York,

15. Jurjus $A$, Sfeir R, Bezirdjian R. Unusual variation of the arterial pattern of the human upper limb. Anat Rec. 1986; 215. p. 82-83.

16. Treves FB, Rogers L. In: The upper extremity. Surgical applied anatomy. $11^{\text {th }}$ edn. 1947; pp. 230-31, Cassell \& Co. Ltd. London.

17. Madhyastha S, Nayak SR, Krishnamurthy A, D'Costa S, Jose AA, Bhat KM R. Case report of high origin of radial, ulnar, and profunda brachii arteries, its clinical implications and review of the literature. J Vasc Bras. 2009; 8. p. 374-78.

18. M itra B, Sadhu A, M eyur R, Sarkar S. High up division of brachial artery into laterally placed ulnar artery and medially placed radial artery. Int J Anat Var. 2013; 6. p. 64-65. 19. Teli C, Kate NN, Paarthipan N. High division and variation in brachial artery branching pattern. IOSR Journal of Dental M edical Sciences. 2013; 3(6). p. 68-70.

20. M ehta V, Arora J, Suri RK, Rath G. Unilateral anomalous arterial pattern of human upper limb- Anatomical description and clinical implications. Sultan Qaboos University Medical Journal. July 2008. 8(2). p. 227-230.

21. Singh H, Gupta N, Bargotra RN, Singh NP. Higher bifurcation of brachial artery with superficial course of radial artery in forearm: case report. JKScience. January-M arch 2010; 12(1); p. 39-40.

22. Puspalatha M, Haq I. Bilateral high divisions of the brachial artery - a case report. Anatomica Karnataka. 2010; 4(1).p. 59-61.

23. Rossi Junior WC, Esteves A, Simões JS, Fernandes GJM . Bilateral high division of the brachial artery in one human male cadaver: case report. J. Morphol. Sci. 2011;28. p. 204-7. 